\title{
Research and Application on Human Resource Management Information System in China First-class Hotels
}

\author{
Haiyan Sun ${ }^{1, a}$, Baozhen $\mathrm{Han}^{1, \mathrm{~b}}$ and Chuanbao $\mathrm{Yu}^{1, \mathrm{c}}$ \\ ${ }^{1}$ Qingdao Vocational and Technical College of Hotel Management, Qingdao, Shandong, China \\ ashysf1799@163.com, bylviahbz@126.com, c44373168@qq.com
}

Keywords: Informationlization, Hotel, HR Management, the Westin Guangzhou

\begin{abstract}
The electronic human resource management (e-HRM) is adopted in the hotel industry widely nowadays. However, case studies are rare. This study set the Westin Guangzhou as sample, and implemented the research on the Infomationization impact on the human resource management in hotels. The result indicated that, first, the human resource management in the hotel industry had entered the information age; moreover, e-HRM could provide information sharing and decision basis when it comes to the stage of human resource strategy deploying. Unfortunately, e-HRM, due to the character of quantification, had a limitation on satisfying the personality requirement of the human resource management. As a result, the key factors to optimize the implementation of e-HRM in the hotel industry are information technology or information system enhancement and staff training on working habit.
\end{abstract}

\section{Introduction}

Human resource management emerged in the late $1970 \mathrm{~s}$, as a response to the increasingly fierce competition and the increasing liquidity of the market, its purpose is to coordinate the relationship between the employees, to ensure the staff's efforts to focus on for best performance in the organization [1].In the 1990s, European human resource management is the core of the academic research field, a large number of studies have focused on the problem of the personnel management of cross-cultural in European context at this stage[2].

The application of information technology in human resource management can improve the operating model of human resources, improve human resources work participation and internal activities range [3].And, more importantly, the advanced human resources system can bring great value to the enterprise and improve the status of human resources in the whole enterprise [4].With the development of technology, the hotel staff can demand their own personnel information through a variety of technology terminals [5].If the enterprise to obtain competitive advantages on the context of network era, it is necessary to establish a network consist of global each district organization that can make products, personnel, information, etc. of worldwide quickly convey to each connection point relying on the network .on the context of network era, It will require human resource managers in companies must think in a new global way of thinking to rethink the role of human resources management enterprises, the revolution enterprise's recruitment, training, performance appraisal, compensation management will face especially under the background of networking [6].

At the aspect of hotel HR aspect, the research content is mostly scattered as one branch of human resource management function, rarely discuss it deeply from a strategic and overall perspective. The specific study: recruitment website is an important platform for the hotel human resources recruitment network, also an important carrier of enterprise and job seekers to use network recruiting [7]. To sum up, although the domestic and foreign scholars for the Informatization of human resource management, but the specific content related to hotel industry is relatively poor. Especially in the domestic, although research has pointed out that the hotel e - HR's inevitability and its benefits, but the aspects of research are narrow. Based on this, this article will survey to obtain the first-hand information, discusses the performance of Hotel e-HR in the actual operation, exploring the influence of information on the hotel human resources management, to provide the decision-making for the hotel human resources management strategy. 


\section{The process and methods of research}

This study selected HNA Westin Hotel in Guangzhou as a case study object, mainly through interventional observation and in-depth interviews to obtain the survey data.

Case Selection: Guangzhou HNA Westin Hotel is the first international five star hotel chain, which opened in Guangzhou, belongs to the Starwood (Starwood Hotels \& Resorts Worldwide, Inc.).Its international standardization management of human resource management, covering design, human resources, human resource planning, recruitment and personnel assessment, personnel use and allocate, personnel risk, performance management, salary management, personnel training, career management, labor relations, the construction of organizational culture, leaders and human resources development and management, etc. Based on this, the object of case study has certain representativeness in the human resources management, can provide scientific and detailed data for this study.

Gold coach system is a set of equipment combined with hardware and software where digital video technology is introduced into the action teaching and training. Its main functions are the acquisition of scene video (the real-time recording of the technical actions that the students perform with cameras, making the collection and record of scenic digital video come true. Multiple cameras can be used for shooting from different angles with synchronization), the display of action video (with the adoption of advanced live broadcast technology and the need to analyze the coach's actions, increase the rate of forward and reverse playback and manually operate frame by frame image display, etc.) and the display of action video with synchronization and comparison (display two different motion videos at the same time and compare the differences between them). In addition, it can also function to analyze manual drawing based on video, contrast the superposition of action video and freeze actions, etc.

In-depth Interviews: The author has a depth interview on all staff of the hotel human resources, get 10 total sample on January 17, 2011 to February 22, 2011, among which, the human resources manager has a decade of hotel human resources management experience and several hotel work experience, the training manager of human resources has 3 years' work experience in personnel recruiting, the vice manager of human resources manager assistant is responsible for maintaining the hotel's personnel system, there are $80 \%$ of the work that need to use information systems to complete every day. The above knowledge background and experience of the sample ensure it can provide detailed and reliable information for this study. Interview content mainly divided into five parts, namely: today's hotel industry human resources management informationization level; E-HR in hotel for the positive and negative effects of work; E-HR in hotel for the positive and negative effects of employees; E-HR in hotel influence on the human resources strategy; E-HR in hotel on hardware equipment. Closed questions and open questions are used in this interview.

\section{The influence of Informationization on the hotel human resources management}

E - HRM's Impact on Hotel Management: On the one hand, the informationalized channels of recruitment are more convenient and efficient. Network has the advantages of low cost, high efficiency and convenience, more and more enterprises and job seekers take job application and recruitment on the net as the main ways of working, it broke through the time and geographical limitations, made hotel recruiters can get a large number of candidate human resources market. It is thus clear that, way of informatization has brought the hotel relatively significant cost savings, with direct economic benefits, but also brought great challenge to the hotel. First of all, based on information is not suitable for all hotel jobs. Secondly, the network of "information explosion" and the "information lags" make hotel recruiting director Influenced by the interference. Once more, the network recruitment has speeded up the turnover of the hotel, which is not conducive to the sustainable development of its human resources. In conclusion, under the background of informatization, the hotel human resources recruitment has changed the traditional way, mostly adopt the network recruitment especially entrust specialized recruitment agencies website for information release, greatly save the recruitment costs, with direct economic benefits, but the information of recruitment approach has certain limits, and the "information explosion" and the "information lags" 
increase the hotel's workload, accelerate the turnover is not conducive to the sustainable development of the hotel human resources.

E-HRM's Impact on Hotel Training Management: The introduction of information management in training system can make the training more lively and interesting, and make students feel the training effect more intuitively. Informationization training system will reduce the trainer for the training effect of control. First, the system of training feedback report may be not true. Second, if the user and the user to rely too much on electronic system, once the system malfunction may result in the whole training could not be; Finally, the system between incompatible instead affects the work efficiency, once the system upgrade or data migration, will result in all the data inputted manually, which increases the new workload. Thus, the hotel human resources management in the information technology training system because of its vividness, etc. to optimize the training process of employee training at present, but it's hard to trainer to real control the training effect, and if the users and by the users of the system don't have the information work idea, it may be difficult to achieve its overall advantage.

E - HRM's Impact on Hotel Personnel Management: In personnel management, the positive performance of informationalized mainly concentrated in the personnel administrative examination and approval links, informationization can greatly improve the work efficiency (Figure 1 shows).First of all, the informationization management needs to be initial information input, once the initial information entry work not complete or incomplete, it will seriously affect the operation of the whole system. Second, in the personnel examination and approval, if managers have no consciousness of informationization examination and approval, the may approval appear a large number of electronic product overstock, causing the chaining approval lag, on the contrary reduces the working efficiency; More importantly, the EPR system doesn't have search function, if an omission happens during approval, it can take several times to confirm and correct error link. On the contrary affects its efficiency. Again, many information systems between systems cannot be compatible currently; unable to export the ideal statements, greatly limits the personnel work.

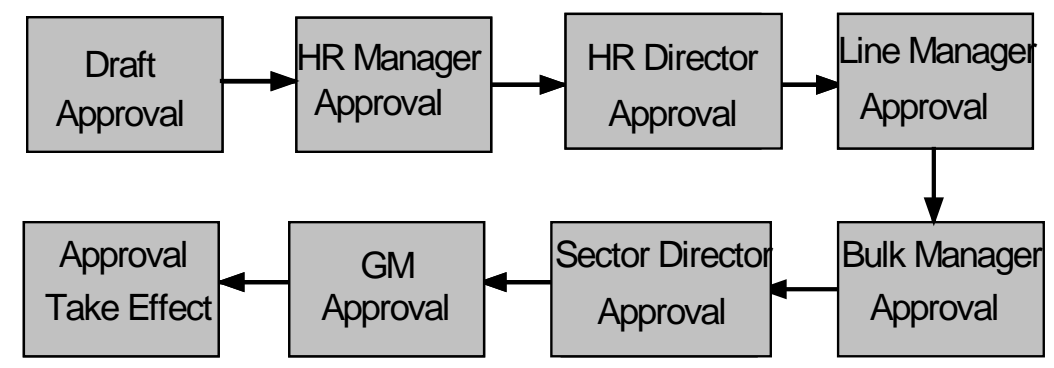

Fig.1 HR and administrative approval process in Westin Hotel

E - HRM's Influence on the Strategic Management of HR: The informationization of hotel human resources management has positive influence on the human resources strategy, also has certain limitation, specific performance is as follows. E - HRM in the strategic management of human resource has the function of information sharing and decision-making basis. On one hand, e - HRM can provide information for the hotel human resources strategy to share the convenience, this positive effect especially in the international hotel group. On the other hand, e-HRM can provide decision basis for the hotel human resources strategy. Respondents agreed that e - HRM can provide a complete set of personnel data to guide its strategic decisions, such as staff turnover rate report, employee satisfaction, training result report, recruitment success rate can provide a basis for its strategic decisions. So, the hotel human resources strategic decision is scientific to a large extent depends on the e - the accuracy of all kinds of basic data HRM provides. Thus, e-HRM is the important component of the hotel human resources strategy of the integral. The study show that the informationization degree of acceptance and use of the related to age, gender, personality, but the current hotel e - HRM doesn't realize the personalized customization. So, the hotel human resources strategy can't completely rely on the system of data on a certain extent, and the experience of their 
own decision-makers limits the application of e-HRM in the hotel human resources strategy policy level on a certain extent. Above all, e-HRM can provide information sharing and decision-making basis for the hotel human resources strategy, but its quantitative characteristics cannot completely meet the personalized needs of human resource management, its application has certain limitations.

\section{Conclusions}

The case study results show that the informatization has the influence of human resource management in international hotel is as follows: first, the high star hotel human resources management has entered the information age, the overall trend will continue, but application level will be varied from its content; Second, informatization greatly saves the hotel human resources recruitment costs, but still has a certain position limits, "information explosion" and the "information lags" can increase the hotel's workload, and accelerate turnover, it is not conducive to the sustainable development of the hotel human resources; Third, hotel information technology training system can optimize the training process and inspire staffs' enthusiasm, but it is difficult to control the training effect, the overall advantages of implementation is affected by employees work idea; Fourth, the information can greatly improve the efficiency of the personnel of the administrative examination and approval work, but the personnel management informatization and artificial way also has many negative effects, some employees are not used to the way of informationization work which will affect the work efficiency, and there are serious system compatibility problems; Fifth, e-HRM can provide information sharing and decision-making or the hotel human resources strategy basis, but its quantitative characteristics cannot completely meet the personalized needs of human resource management, its applications is limited. Based on the above conclusions, the author consider that the hotel human resources management should take the advantage of advantages of information technology, the key lies in the perfect system and the cultivation of the employees work habits.

\section{References}

[1] Susan,M.Human resource management in smaller firms:A contradiction in terms [J].Human Resource Management Review,2006,(16):467 477.

[2] Paul,S.,Jeanm,H.European human resource management in Transition[J ].European Management Journal,1995,(13):234 235.Management,2008,(27):30 41.

[3] HR Focus, How HRIS is transforming the workplace - and HR's role [ J ] .HR Focus, 2004,(3):10 13.

[4] Lawler,E.,Mohr man,S.HR as a strategic partner:What does it take to make it happen [J] .Human Resource Planning,2003,(3):15 29.

[5] Robert,W.Predicting is difficult,especially about the future:Human resources in the new millennium [J] . Hospitality Management,1999,(18):443 456.

[6] Wang Zaoxian, Ma Fengguang. Human resource management of network [J]. Market modernization, 2007, (14): $291 \sim 293$.

[7] Liu Zhao tong. Network: an empirical study of human resources recruitment [D]. Nanjing: Nanjing University of science and technology, 2007. 